\title{
Isolation, characterization and the functional properties of cellulosic arabinoxylan fiber isolated from agricultural processing by- products, agricultural residues and energy crops
}

\author{
Madhav P. Yadav, ${ }^{1}{ }^{*}$ Madhuvanti S. Kale ${ }^{2}$, Kevin B. Hicks ${ }^{1}$ and Kyle Hanah ${ }^{2}$
}

\begin{abstract}
Water insoluble cellulosic arabinoxylan fibers were prepared from low-valued agricultural processing by-products, agricultural residues and energy crops by removing the alkali-extractable hemicelluloses and processing the alkali insoluble material under high temperature and high shear conditions. The yield of these fibrous plant materials varied from 14.3 to $59.90 \%$ and most of them contained more than $90 \%$ insoluble dietary fiber. Sugar composition and glycosyl-linkage analysis show that they are composed of cellulose and arabinoxylans indicating that they have a typical cellulosic arabinoxylan structure. They have
\end{abstract}


33 very high water holding capacity varying from 6.374 to $74.33 \mathrm{~g} / \mathrm{g}$ (water/fiber), indicating their

34 usefulness in many food system applications as moisture management aids and texturizing

35 agents. Their ORAC values vary from 352 to $1560 \mu$ mole Trolox/100 gram showing that they

36 have the ability to provide antioxidant activity in foods, as well as offering other functionality

37 and health-promoting benefits of dietary fiber.

39 Keywords: Insoluble fiber, agricultural processing by-products, water holding capacity,

40 antioxidants, rheology.

41

\section{Introduction:}

43 Lignocellulosic materials are abundant and renewable biological resources, which contain numerous components that could be valuable products if they are economically isolated and marketed. Along with the three major polymeric components, namely cellulose, hemicellulose,

46 and lignin, lignocellulosic materials also contain other minor components, such as extractives

47 (phenolics, lipids, etc.), pectins and proteins (Zhang et al., 2004 and Fengel et al., 1984). Corn

48 fiber/bran, a renewable resource available in a large quantity, can be a good source of valuable

49 consumer products. Corn fiber makes up about 5 to $10 \mathrm{wt}$. \% of the total weight of the corn

50 kernel. Primarily, it consists of residual starch (10 to $20 \mathrm{wt}$ \%), hemicelluloses (40 to 50 wt. \%),

51 cellulose (15 to 25 wt. \%), phenolic compounds (3 to 5 wt. \%), protein (5 to $10 \mathrm{wt}$. \%) and some

52 oils (Wolf et al., 1953, Chanliaud et al., 1995, Yadav et al., 2006, 2007 a, b, 2010). Byproducts

53 obtained from agricultural processing operations, such as corn stover, rice straw and cereal brans,

54 are rich in lignocellulose. Fibers isolated from these sources could be useful in numerous

55 applications across a wide range of industries, including the food, biofuels, cosmetics, medicine, 56 packaging, construction and animal feed sectors (Reddy and Yang, 2005). The food industry, in

57 particular, is a large potential market for products made from lignocellulosic biomasses, which

58 consist of nutritionally beneficial dietary fibers with good functional properties. Dietary fiber-

59 based ingredients are often used as viscosity building additives and bulking agents in foods,

60 which impart food products with desirable mouth feel and texture while decreasing fat and

61 calorie-content and providing nutritional benefits in the form of increased satiety, improved

62 blood glucose and cholesterol levels, reduced gut transit times and stool bulking (Gray and

63 Tainter 1941; Faivre and Boutron 1991; Reddy et al., 1989; Buttriss and Stokes, 2008), among

64 others. The preparation of insoluble dietary fiber-based bulking agents from corn bran and oat 
65 hulls has been reported previously (Inglett, 1998, Inglett and Carriere, 2001). These materials

66 were reported to have high water holding capacity and viscosity, and serve as fat replacers in 67 food formulations.

68 In this study, highly functional insoluble fibers were isolated from many agricultural sources 69 using an improved process consisting of very high shear in the presence of alkali, and their 70 chemical composition and rheological and functional properties were thoroughly evaluated.

71 These cellulosic arabinoxylan fibers show great promise as health promoting and highly

72 functional bulking and viscosity building agents for use in the food and non-food industries.

73

74 2. Materials methods

75 2.1. Materials

76 Plant materials were obtained from various sources as follows: Corn bran (Bunge Milling, Inc., 77 St. Louis, MO), Corn stover (Lawrence Shrawder, a Private Farm, Kempton, PA), Rice fiber 78 (SunOpta Ingredients, Cedar Rapids, IA), Wheat bran (Deibel Laboratories, Bethlehem, PA), 79 Wheat straw (Hougar Farms LLC, Coatesville, PA), Switch grass (ARS lab at University Park, 80 PA), Miscanthus (University of Illinois at Urbana-Champaign, Champaign, IL), Sugarcane 81 bagasse (Southern Regional Research Center, ARS, USDA, New Orleans, LA), Sorghum brans 82 (Nu Life Market, Scott City, KS), Barley hulls (Osage Bio-Energy, Glen Allen VA), Barley 83 straws (Foundation Seed Farm of the Virginia Crop Improvement Association in Mt. Holly, 84 Virginia) and Carrot pomace (Grimmway Farms, Bakersfield, CA). They were ground to a 2085 mesh particle size using a Wiley mill. Termamyl ${ }^{\circledR}$ was a gift from Novozymes, Inc., (Davis, 86 CA). Sodium hydroxide and hydrochloric acid were obtained from Sigma-Aldrich (St. Louis, 87 MO). All chemicals were reagent grade.

\subsection{Standard proximate analyses}

90 Protein $(\mathrm{N} \times 6.25)$ and ash contents of all samples were determined using AACC Approved 91 Methods 46-30 and 08-01 respectively (AACC International, 1995). Crude fat content was 92 determined using the ANKOM XT10 Extractor with hexane as the extracting solvent. Starch 93 content was determined using a total starch assay kit (Megazyme, Inc., Wicklow, Ireland ) based 94 on the use of thermostable $\alpha$-amylase and amyloglucosidase (McCleary et al., 1997). 
98 Insoluble dietary fiber (IDF), soluble dietary fiber (SDF), total dietary fiber (TDF) and neutral

99 detergent fiber (NDF) in CAF were determined following the standard A2000 automated fiber

100 analyzer procedure (ANKOM Technology, 2011).

101

102 2.4. Preparation of cellulosic arabinoxylan fiber

103 The plant material (200 g) was added to mechanically stirred $1150 \mathrm{~mL}$ hot water $\left(85{ }^{\mathrm{O}} \mathrm{C}\right)$. The

$104 \mathrm{pH}$ was adjusted to about 6.8 by adding $50 \%$ sodium hydroxide solution. $2 \mathrm{~g}$ of $\alpha$-amylase

105 Termamyl $^{\circledR}$ ) was added and stirred for 1 hour to hydrolyze starch. The pH of the slurry was

106 raised to 11.5 by adding $50 \%$ sodium hydroxide and stirred using a mechanical stirrer at $85{ }^{\circ} \mathrm{C}$

107 for an additional 30 minutes to completely deconstruct the material. During the reaction, $\mathrm{pH}$ was

108 maintained at 11.5 by adding $50 \% \mathrm{NaOH}$ and the reaction volume was maintained by adding

109 water as needed to compensate water loss due to evaporation. The hot slurry of the deconstructed

110 material was immediately sheared using a high speed Polytron (PT 10/35 GT) equipped with 12

$111 \mathrm{~mm}$ probe (Kinematica Inc., Bohemia, NY) at 10,000 rpm for 1 hour. The solid residue was

112 separated from the reaction mixture by centrifugation at $14,000 \mathrm{Xg}$ for 10 minutes, suspended in

$1132 \mathrm{~L}$ boiling water and stirred using a mechanical stirrer for 5 minutes. The hot suspension was

114 again sheared at $10,000 \mathrm{rpm}$ for 5 minutes. The sheared material was allowed to cool at room

115 temperature and centrifuged at $14,000 \mathrm{Xg}$ for 10 minutes to separate the solid, and hot water

116 washing and shearing cycles were repeated till a clear supernatant was obtained. For most of

117 materials two repetitions (three total washings) were needed to get a clear supernatant. The final

118 solid residue was collected, suspended in water and dried by drum or spray drying.

\subsection{Determination of sugar composition}

121 The sugar composition of CAF samples was determined using National Renewable Energy

122 Laboratory Analytical Procedure (Chiu et al., 2008). Briefly, $0.3 \mathrm{~g}$ sample was suspended in 3

$123 \mathrm{~mL} 72 \%(\mathrm{w} / \mathrm{w})$ sulfuric acid in a test tube, mixed and incubated at $30^{\circ} \mathrm{C}$ for $1 \mathrm{~h}$ with intermittent

124 stirring every 5 to 10 minutes. The sample suspension was transferred into a $100 \mathrm{~mL}$ Pyrex glass

125 bottle using $84 \mathrm{~mL}$ water, which also diluted the acid to $2.48 \%$. The bottles containing samples

126 and standard sugars were autoclaved at $121^{\circ} \mathrm{C}$ for $1 \mathrm{~h}$. After cooling to room temperature,

127 aliquots of $5 \mathrm{ml}$ were taken and their $\mathrm{pH}$ was adjusted between 5 and 7 followed by

128 centrifugation. The supernatant was filtered and the filtrate was analyzed for sugars using

129 Agilent 1200 HPLC that included a BioRad Aminex HPX-87H column at $60{ }^{\circ} \mathrm{C}$ and an RI

130 detector. The mobile phase consisted of isocratic $5 \mathrm{mM} \mathrm{H}_{2} \mathrm{SO}_{4}$ eluent at a flow rate of 0.6 
$131 \mathrm{~mL} / \mathrm{min}$. The quantification of each sugar was done using the calibration curve of standard

132 sugars prepared under the same conditions.

\subsection{Determination of glycosyl-linkage composition}

135 The sugar linkage composition of the CAFs was determined by gas chromatography-mass

136 spectrometry (GC-MS). The sample was permethylated, depolymerized, reduced and acetylated.

137 The resulting partially methylated alditol acetates (PMAAs) were analyzed by GC-MS (Heiss et

138 al., 2009: York et al., 1986). Briefly, about $1 \mathrm{mg}$ of the sample was suspended in $200 \mu \mathrm{l}$

139 Dimethyl Sulfoxide (DMSO) and stirred for 3 days, followed by treatment with sodium

140 hydroxide (15 $\mathrm{min}$ ) and methyl iodide (45 $\mathrm{min}$ ) at room temperature, repeated twice. The

141 permethylated polymer was hydrolyzed with 2 M TFA ( 2 hours in a sealed tube at $121{ }^{\circ} \mathrm{C}$ ),

142 reduced with $\mathrm{NaBD}_{4}$ and acetylated using acetic anhydride/TFA. The resulting partially

143 methylated alditol acetates (PMAAs) were analyzed by GC-MS (Agilent 7890A GC interfaced to

144 a 5975C mass selective detector in electron impact ionization mode). The separation was

145 performed on a 30 meter Supelco SP-2331 bonded phase fused silica capillary column.

147 2.7. Determination of water holding capacity

148 The water holding capacity of CAF was determined following the published procedure

149 (Elhardallou \& Walker, 1993) and AACC method 88-04 (AACC, 1995) with some modification.

150 Briefly, 0.5 g CAF sample in triplicates was weighed in a polypropylene centrifuge tube with

151 screw cap. To each tube, $24.5 \mathrm{~mL}$ distilled water were added and the sample was sheared using a

152 high speed polytron at 10,000 rpm for 2 minutes and at 15,000 rpm for 1 minute. The tubes were

153 placed on shaker at room temperature and shaken at a moderate speed for about 24 hours. Then

154 they were centrifuged at $1,000 \mathrm{~g}$ for 15 minutes. After decanting the excess water, the tubes were

155 inverted to completely remove any residual water. Each tube was weighed, and the amount of

156 water held was calculated by subtracting the weight before water treatment and the water holding

157 capacity (WHC) of the sample was calculated using the following equation:

159 where $g_{\text {water }}(\mathrm{g})$ and $g_{\text {sample }}(\mathrm{g})$ are the weight of water held by the sample and the original

160 weight of dry sample respectively. 
163 Antioxidant activity of the CAF samples was determined using the ORAC assay, and expressed

164 as Trolox equivalents/100 g sample. The ORAC values of CAF were determined using the

165 published procedure (Huang et al., 2002; Ou, B., et al., 2002).

\subsection{Rheological studies}

168 Rheological properties of CAF samples were measured using a rotational rheometer (Anton Paar Modular Compact Rheometer 102, Anton Paar GmbH, Ashland, VA) with a concentric cylinders geometry. The samples were prepared by shearing $4 \% \mathrm{w} / \mathrm{w}$ suspensions of the CAF in water at $15000 \mathrm{rpm}$ for $3 \mathrm{~min}$ followed by $10000 \mathrm{rpm}$ for 2 min using a Polytron mixer (Kinematica Inc., Bohemia, NY). Flow curves of the samples were developed by measuring viscosity at different

173 shear rates $\left(0.13-130 \mathrm{~s}^{-1}\right)$. Power Law fitting of the flow curves was carried out, using Microsoft

174 Excel, to determine flow consistency index and flow behavior index.

\section{Results and discussion}

\subsection{Preparation of cellulosic arabinoxylan fiber}

178 Cellulosic arabinoxylan fiber (CAF) was prepared from ground plant materials including agricultural processing byproducts such as sorghum bran, corn bran, wheat bran, rice fiber,

180 barley hulls, sugarcane bagasse, carrot pomace, agricultural residues such as corn stover, wheat 181 straw, barley straw etc. and energy crops such as switchgrass and miscanthus according to the 182 scheme shown in Fig. 1. Alkali-soluble hemicelluloses were removed by mechanically stirring 183 the de-starched plant materials in alkaline solution $(\mathrm{pH} \sim 11.5)$ at $85^{\circ} \mathrm{C}$. The alkali insoluble 184 CAF was recovered from the deconstructed reaction mixture by centrifugation. The recovered 185 material was re-suspended in hot water and sheared using high speed homogenization. The 186 suspension of the solid material in hot water and its heating and shearing were repeated till a 187 clear supernatant was seen. Then the final solid residue was collected, suspended in water and 188 dried by drum or spray drying to obtain the final product "CAF".

189 The amount of CAF isolated from different plant materials, following the scheme given

190 in Figure 1, varied from 14.30 to $59.90 \%$ (Table 1). Rice fiber had the highest percent of CAF, 191 which may be attributed to prior alkaline treatment by the manufacturer. Corn stover, wheat 192 straw, miscanthus, sugarcane bagasse, and barley straw yielded more than $40 \% \mathrm{CAF}$, making 193 them all promising feedstocks for commercial-scale production. The remaining plant materials 194 gave less than $20 \%$ yield, but could potentially be used for commercial CAF production if they 195 are readily available, especially if the hemicellulose fractions can also be utilized. 


\subsection{Proximate composition and dietary fiber analysis}

198 Table 2 shows the proximate composition of CAF isolated from all sources. The ash content in

199 these samples was less than 3\% except corn stover (7.29\%) and sugarcane bagasse (9.90\%).

200 Their protein content varied from 0.56 to 2.20 except CAF from sorghum bran, which was rich

201 in protein (5.37 to $23.82 \%$ ). CAF from sorghum bran had 0.91 to $5.42 \%$ residual starch but for

202 all other samples the starch content was less than $0.36 \%$. None of the samples contained

203 significant amounts of fat. As expected, the samples were very rich in neutral detergent fiber

204 (95.50 to 99.75\%). The only exception to this was the CAF from sorghum bran, which had a

205 greater amount of residual starch which could explain the lower fiber content. In most of the

206 samples, more than $90 \%$ of the fiber present was insoluble dietary fiber. CAF from corn bran,

207 corn stover, sorghum bran (black milled), sorghum bran (burgundy milled), barley hulls/straws

208 and carrot pomace showed some soluble dietary fiber which could be due to presence of some

209 water soluble carbohydrate. It is clear that CAFs isolated from all the plant materials were almost

210 pure dietary fiber. They are predicted to be non-caloric in human diets, and should be very useful

211 for making non-caloric food products.

\subsection{Sugar composition of $C A F$}

214 Table 3 shows that the neutral sugars present in CAF from all plant materials are glucose,

215 xylose and arabinose, clearly demonstrating that it has a typical cellulosic arabinoxylan structure.

216 While it is known that the exhaustive extraction of arabinoxylans from cereal cell walls using

217 alkali is not achieved even by very harsh alkaline treatments (Maes and Delcour, 2001), the

218 insoluble residue was previously thought to contain primarily glucose (cellulose) (Inglett and

219 Carriere, 2001) with little to no arabinose and xylose. The amount of glucose varied from about

220 34.78- 73.87\%, while xylose and arabinose contents ranged from 11.69-31.97\%, and 2.04-

221 13.17\% respectively. The true structure of this cellulosic arabinoxylan fiber with respect to the

222 type of association, if any, between the cellulose and arabinoxylan polymers, is not currently

223 known. However, the presence of significant amounts of arabinoxylan in spite of the rigorous

224 purification process used (Figure 1) suggests the presence of very strong covalent or non-

225 covalent associations between the two polymers.

\subsection{Glycosydic-linkage composition of CAF}

228 The glycosydic-linkage composition of CAF isolated from five selected sources (corn bran, rice

229 fiber, wheat straw, miscanthus and sugarcane bagasse) were analyzed (Table 4). CAF from

230 corn bran contained $55.5 \%$ of $(1 \rightarrow 4)$-linked glucose residues, representing cellulose. Most of 
231 xylose residues were present as $(1 \rightarrow 4)$-linked xylopyranose $(\mathrm{Xyl} p)$ backbone, which was

232 highly branched on its $C-2$ and $C-3$ positions. The total percent of unbranched and branched

$233(1 \rightarrow 4)$ linked Xylp was $17.4 \%$. The presence of significant amounts of terminal arabinose,

234 xylose, galactose and glucose (5.1, 5.2, 2.9 and $6.1 \%$ respectively) indicates that the

235 arabinoxylan in corn bran CAF has a highly branched structure, which may contribute to some

236 of its functional properties such as water holding capacity and viscosity. Table 4 also shows the

237 glycosydic-linkage analysis results for CAF from rice fiber, wheat straw, miscanthus and

238 sugarcane bagasse showing results similar to CAF from corn bran with 53.3 to $66.8 \%$ of

$239(1 \rightarrow 4)$-linked glucose residue and about 23.7 to $32.8 \%$ of $(1 \rightarrow 4)$ linked Xyl $p$ residue as the

240 major sugars. It is clear that as in CAF from corn bran, the major portion of carbohydrate

241 polymer in all these CAF samples have a cellulose-like sugar backbone structure. It also

242 demonstrates that though it has a cellulose-like sugar backbone, it does not have a fully

243 cellulose-like structure. It also contains a high percentage (23.7 to $32.8 \%$ ) of xylan in addition

244 to glucose and some arabinose. Unlike CAF from corn bran, the Xyl $p$ present as $(1 \rightarrow 4)$-linked

245 backbone in CAF from these four sources are not highly branched as indicated by their low

246 percent of terminal arabinose, xylose and glucose. The percentage of sugars linked at carbons

2472,3 or 6 position in all of these four samples are lower than CAF from corn bran, which further

248 confirms that they do not have a very highly branched structure. From these results, the nature

249 of the association between two main carbohydrate polymers [(1 $\rightarrow 4)$-linked Xylp (xylan) and

$250(1 \rightarrow 4)$-linked glucan] is still not clear. The less branched structure of arabinoxylan polymer in

251 these materials than that in corn bran CAF may be associated with the lower water holding

252 capacity and viscosity of their suspensions as discussed in following sections.

253 The glycosyl-linkage analysis of CAF from carrot pomace was also performed (data not shown),

254 and was found to be significantly different than that of the other CAFs. It contains a high

255 percentage of $(1 \rightarrow 4)$-linked glucose residues $(67.8 \%)$, but its $(1 \rightarrow 4)$-linked Xylp content $(5.1 \%)$

256 was lower than CAFs from other sources. It also showed a low amount of terminal sugars and

257 less sugars linked at carbons 2, 3 and 6 positions, showing less branched structure than CAF

258 from corn bran.

\subsection{Water holding capacity}

261 Table 5 shows the water holding capacity (WHC) of CAF from the various sources. WHC is

262 known to vary depending upon the carbohydrate composition, branching and molecular structure

263 of the fiber. All of the CAF samples studied showed high water holding capacity, with

264 remarkable variation in the WHC depending upon source and also on the process of drying from 
265 its slurry into solid form. The WHC of these fibers varied from 6.374 to $34.81 \mathrm{~g} / \mathrm{g}$ (water/fiber),

266 with rice fiber CAF showing the lowest WHC. The WHC of CAF from corn bran was much

267 higher than the CAF from all other sources, possibly owing to the unique highly branched

268 structure of its constituent polymers. The drying process to make CAF also had an effect on its

269 WHC as seen in drum and spray dried material form corn bran. The WHC of spray dried CAF

270 from corn bran was much higher $(74.33 \mathrm{~g} / \mathrm{g})$ than the drum dried product $(32.767 \mathrm{~g} / \mathrm{g})$. This

271 could be due to the difference in the particle morphology caused by the two drying techniques,

272 leading to better hydration in the spray dried CAF particles than the drum dried material. This

273 difference was also apparent in the rheological properties of the CAF samples, discussed in

274 section 3.7.

275

\subsection{Antioxidant activity}

Lignocellulosic materials are known to contain significant amounts of phenolic compounds, which can contribute to antioxidant activity in dietary fibers isolated from these materials. Table 6 shows the ORAC values of CAF isolated from different sources. It is clear that all the CAF samples retained a considerable amount of phenolic compounds, leading to significant antioxidant activity in the range of 326 to $1560 \mu \mathrm{mol}$ Trolox/100 gram sample. There is some evidence that the sugar composition, linkages and structural features of polysaccharides may also influence their antioxidant properties (Lo et al., 2010; Chattopadhyay, et al., 2010; Rao et al., 2006). Arabinose in the side chains and unsubstituted and/or monosubstituted xylose on CAF may also contribute to antioxidant activity. Drum dried CAF from corn bran had the highest ORAC value of 1560 Trolox/100 grams (Table 6). A higher ORAC value of drum dried corn bran CAF than the spray dried material from the same source shows that there is an effect of drying method on ORAC value. The reason for this is unknown but may be related to accessibility of phenolic compounds on the fiber. CAFs from wheat bran, sorghum brans, switchgrass, barley hulls and rice fiber had ORAC values above $600 \mu$ mole Trolox/100 grams. The ORAC value in the CAFs from the remaining materials was less than $500 \mu$ mole Trolox/100 292 grams, which is still significant from the nutraceutical perspective. Thus it is clear that CAFs 293 from these plant sources have the ability to provide antioxidant activity in foods in addition to 294 other health-benefits as an insoluble, bulking dietary fiber.

\subsection{Rheological properties}

297 All CAF suspensions showed very high viscosity at $4 \% \mathrm{w} / \mathrm{w}$ and even at lower concentrations 298 (data not shown). The apparent viscosity of the samples at a shear rate of $1.3 \mathrm{~s}^{-1}$ ranged widely 
299 from 0.418 Pa.s for rice fiber CAF to 29.1 Pa.s for the spray dried corn bran CAF. This wide

300 range is probably a result of the different sugar compositions of the materials as well as the

301 branching of the constituent arabinoxylan polymers. In general, the samples with higher

302 arabinoxylan content and more branching showed higher viscosity values. This data correlated

303 well with the WHC of the samples, with the samples that had high WHC showing

304 correspondingly high viscosity.

305 All the samples also showed shear thinning behavior (Table 7), with flow consistency index

$306(\mathrm{~K})$ values ranging from 0.727-36.45 $\mathrm{Pa} . \mathrm{s}^{\mathrm{n}}$ and flow behavior index $(n)$ values ranging from

307 0.25-0.5. The low values of $n$ indicate that all of the CAF samples showed a significant degree of

308 shear thinning, implying that even though they are highly viscous materials at low shear rates,

309 they lose much of their viscosity at higher shear rates. Such high degree of shear thinning can be

310 an advantage in food processing operations, where these CAF suspensions can be used to impart

311 high viscosity to the product while still being easy to pump at high shear rates.

312 It is interesting to note that the $n$ value was affected by the drying method, with drum dried and

313 spray dried corn bran CAFs showing $n$ values of 0.5 and 0.25 respectively. It is likely that the

314 difference in particle morphology of the materials had an effect on the particle size and surface

315 characteristics in the swollen state, leading to different levels of inter-particle friction and

316 particle orientation in the flow field.

317 In addition to the difference in apparent viscosity, $\mathrm{K}$ and $n$ values, the drying method also

318 seems to affect the hydration of the particle and the effect of shearing on the viscosity of the

319 suspension. Figures 2( $\mathrm{a}$ and $\mathrm{b}$ ) show comparisons of the flow behavior of $4 \%$ suspensions of

320 drum dried and spray dried CAF from corn bran and sorghum bran (Burgundy milled), prepared

321 with and without shearing. It is clear that, in both cases, the drum dried CAF did not show high

322 viscosity when prepared without any shearing (empty squares). When these samples were

323 sheared for 3 minutes at $15000 \mathrm{rpm}$ followed by 2 minutes at $10000 \mathrm{rpm}$, the viscosity increased

324 significantly (filled squares). The spray dried CAF from both sources showed very high

325 viscosity (equivalent to drum dried samples with shear) even without shearing (empty triangles).

326 All samples were allowed to hydrate for at least 3 hours before measurement of viscosity. When

327 the spray dried samples were sheared, the viscosity increased even further (filled triangles).

328 Thus it is clear that the drum dried CAF samples required shearing along with hydration in order

329 to give high viscosity. Spray dried samples, on the other hand, showed high viscosity even with

330 no shearing if they were allowed to hydrate sufficiently. Shearing of these spray dried samples

331 lead to even higher viscosities which could not be obtained with drum dried samples at the same

332 level of shearing. Thus, drying method has a significant effect on the rheological properties of 
333 CAFs, with spray dried samples showing more shear thinning and higher viscosity even without

334 shearing as compared to drum dried CAF.

\section{4. Conclusion}

336 Cellulosic arabinoxylan fiber (CAF) is a highly functional value-added product that can be 337 prepared with high yields ( 14.3 to $59.90 \%$ ) from many low value agricultural processing by-

338 products, agricultural residues and energy crops. The CAFs consisted almost entirely of dietary

339 fiber, making them suitable as non-caloric bulking and texturizing agents in food products. These

340 water insoluble materials are rich in glucose and also contain significant amounts of xylose and

341 arabinose, in the form of arabinoxylan polymers, accounting for almost half of the total

342 carbohydrate in some cases. The cellulose and arabinoxylan polymers are strongly associated,

343 but nature of the association is not clear. CAF from corn bran had a highly branched structure,

344 and also showed the highest ORAC value among all the samples. Corn bran CAF also gave the

345 highest values of water holding capacity (WHC) and viscosity. CAFs from other sources also

346 showed high values of WHC and viscosity, and they all showed shear thinning flow behavior.

347 The method used for drying the CAF (drum drying versus spray drying) had a significant effect

348 on the WHC, viscosity and flow behavior; with spray dried CAF showing higher WHC and

349 higher viscosity even without shearing as compared to drum dried CAF from the same source.

350 Owing to their high functionality and non-caloric nature, CAFs produced from low-valued

351 agricultural by-products are a very interesting and commercially valuable class of health-

352 promoting, insoluble dietary fiber based bulking agents, viscosifiers and texturizing agents for

353 use in the food industry and beyond.

\section{Acknowledgements}

356 We would like to thank Stefanie Simon and Rich Cook for their technical assistance. The

357 glycosyl linkage analysis work was supported by the Chemical Sciences, Geosciences and

358 Biosciences Division, Office of Basic Energy Sciences, U.S. Department of Energy grant (DE-

359 FG02-93ER20097) to Parastoo Azadi at the Complex Carbohydrate Research Center.

\section{References}


ANKOM Technology. A2000 automated fiber analyzer, Ankom Technology, Macedon, NY; 2011. 〈http://www.ankom.com/media/documents/Method_6_NDF_4013011_A200,A200I.pdf〉.

Buttriss, J.L. and Stokes C.S. (2008). Dietary fiber and health: An overview. Nutrition Bulletin, $33,186-200$

Chanliaud, E., Saulnier, L., and Thibault, J. F. Alkaline extraction and characterization of heteroxylans from maize brans. Journal of cereal science, 21:195-203, 1995.

Chattopadhyay, N., Ghosh, T., Sinha, S., Chattopadhyay, K., Karmakar, P., and Ray, B. (2010). Polysaccharides from Turbinaria conoides: Structural features and antioxidant capacity. Food Chemistry, 118, 823-829.

Chiu, C-W., Henley, M. J., Zallie, J. P., Jeffcoat, R. (1998). Bulking agents and processes for preparing them from food gums. U.S. Patent 5,811,148.

Elhardallou, S. B., \& Walker, A. F. (1993). The water-holding capacity of three starchy legumes in the raw, cooked and fibre-rich fraction forms. Plant Foods for Human Nutrition (Formerly Qualitas Plantarum), 44(2), 171-179.

Faivre J, Doyon F, Boutron M, The ECP calcium fibre polyp prevention study. Eur J Cancer Prevent 1: 83-89, 1991.

Fengel, D.; Wegener, G. Wood: Chemistry, Ultrastructure,Reactions; Walter de Gruyter \& Co.: Berlin, 1984.

Gray H, Tainter ML, Colloid laxatives available for clinical use. Am J Dig Dis 8: 130-139, 1941

Heiss, C., J.S. Klutts, J. S., Wang, Z., Doering, T. L., and Azadi. P. (2009). The structure of Cryptococcus neoformans galactoxylomannan contains b-D-glucuronic acid. Carbohydr. Res. 344, 915-920.

Huang, D., Ou, B., Hampsch-Woodill, M., Flanagan, J. A. and Prior, R. L. (2002). Highthroughput assay of oxygen radical absorbance capacity (ORAC) using a multichannel liquid handling system coupled with a microplate fluorescence reader in 9 -well format. $J$. Agric. Food Chem., 50, 1815-1821.

Inglett, G.E. (1998) Dietary fiber gels for calorie-reduced foods and method for preparing the same. US Patent No. 5,766,662

Inglett G.E. and Carriere, C.J., (2001). Cellulosic fiber gels prepared from cell walls of maize hulls. Cereal Chem. 78: 471-475

Lo, T. C. T., Chang, C. A., Chiu, K. H., Tsay, P. K. and Jen, J. (2011). Correlation evaluation of antioxidant properties on the monosaccharide components and glycosyl linkages of polysaccharide with different measuring methods. Carbohydrate Polymers, 86, 320-327.

Maes, C., and Delcour, J.A. (2001) Alkaline hydrogen peroxide extraction of wheat bran nonstarch polysaccharides. Journal of Cereal Science, 34, 29-35 
418

419

420

421

422

423

424

425

426

427

428

429

430

431

432

433

434

435

436

437

438

439

440

441

442

443

444

445

446

447

448

449

450

451

452

453

454

455

456

457

458

459

460

461

462

463

464

465

466

McCleary, B. V., Gibson, T. S. and Mugford, D. C. (1997). Measurement of total starch in cereal products by amyloglucosidase - $\alpha$-amylase method: Collaborative study. J. AOAC Int., 80 , 571-579.

Ou, B., Huang, D., Hampsch-Woodill, M., Flanagan, J. A., and Deemer, E. K. (2002). Analysis of antioxidant activities of common vegetables. J. Agric. Food. Chem., 50, 3122-3128.

Rao, R. S. P., and Muralikrishna, G. (2006). Water soluble feruloyal arabinoxylans from rice and ragi: Changes upon malting and their consequences on antioxidant activity. Phytochemistry, 67, 91-99.

Reddy BS, Engle A, Katsifis S, Simi B, Bartram HP, Perrino P, Mahan, C, (1989). Biochemical epidemiology of colon cancer: Effect of types of dietary fibre on fecal mutagens, acid and neutral sterols in healthy subjects. Cancer Res 49: 4629-4635.

Reddy, N. and Yang, Y. (2005). Biofibers from agricultural byproducts for industrial applications. Trends in Biotechnology, 23: 22-27.

Sluiter, A., Hames, B., Ruiz, R., Scarlata, C., Sluiter, J., Templeton, D. and Crooker, D. (2008). Determination of Structural Carbohydrates and Lignin in Biomass. National Renewal Energy Laboratory Analytical Procedure, 1-18.

Thompson, J. B. Process for preparing cellulose. US Patent 4,486,459, 1984

Vail, W. J. Process for recovery of cellulose. US Patent 5,057,334, 1991

Voragen, A. G. J. (1998). Technological aspects of functional food-related carbohydrate. Trends Food Sci Technol 9:328-335.

Wolf, M. J., MacMasters, M. M., Cannon, J. A., Rosewell, E. C., \& Rist, C. E. (1953). Preparation and some properties of hemicellulose from corn hulls. Cereal Chemistry, 30, 451-470.

Zhang, Y.-H. P.; Lynd, L. R. (2004). Toward an aggregated understanding of enzymatic hydrolysis of cellulose: Noncomplexed cellulase systems Biotechnol. Bioeng. 88: 797824.

Yadav, M. P., Johnston, D. B., Hotchkiss, A. T., \& Hicks, K. B. (2007a). Corn fiber gum: a potential gum arabic replacer for beverage flavor emulsion. Food Hydrocolloids, 21, 1022-1030.

Yadav, M. P., Johnston, D. B., Hicks, K. B., \& Nothnagel, E. A. (2006). The role of lipids and protein components in the emulsification properties of gum arabic and corn fiber gum. Foods and Food Ingredients Journal, 211(3), 245-252.

Yadav, M. P., Moreau, R. A., \& Hicks, K. B. (2007b). Phenolic acids, lipids, and proteins associated with purified corn fiber arabinoxylans. Journal of Agricultural and Food Chemistry, 55, 943-947. 
467

468

469

470

471

472

473

474

475

476

477

478

479

480

481

482

483

484

485

486

487

488

489

490

491

492

493

494

495

496

497

498

499

500

501

502

503

504

505

506

507

508

509

510

511

512

513

514

515

516

517
Yadav, M. P., Cooke, P., Johnston, D. B., \& Hicks, K. B. (2010). Effect of Protein Rich Components on the Emulsifying Properties of Corn Fiber Gum. Cereal Chemistry, 87(2), 89-94.

York, W. S., Darvill G. A., McNeil, M., Stevenson, T. and Albersheim, P. (1986). Isolation and characterization of plant cell walls and cell wall components. Methods in Enzymology, 118: 3-40 
518

519

520

521

522

523

\section{Tables}

Table 1: Isolation of CAF from Plant Materials (\% Yield, dry weight basis) ${ }^{\mathrm{a}}$

\begin{tabular}{|l|l|}
\hline CAF Sources & \% Yield \\
\hline Corn bran & 20.05 \\
\hline Corn stover & 40.20 \\
\hline Rice fiber & 59.90 \\
\hline Wheat bran & 14.30 \\
\hline Wheat straw & 53.10 \\
\hline Switchgrass & 32.70 \\
\hline Miscanthus & 56.70 \\
\hline Sugarcane bagasse & 52.00 \\
\hline Sorghum bran (Black) & 25.84 \\
\hline Sorghum bran (Sumac) & 38.50 \\
\hline Sorghum bran (Burgundy) & 19.32 \\
\hline Barley hulls & 26.85 \\
\hline Barley straws & 49.75 \\
\hline Carrot pomace & 14.80 \\
\hline
\end{tabular}

${ }^{\mathrm{a}}$ Weight percent based on de-starched biomass 
533 Table 2: Proximate Composition and Dietary Fiber Content of CAF Isolated from Plant Materials (d.w.b.)

\begin{tabular}{|c|c|c|c|c|c|c|c|c|}
\hline CAF Sources & Ash & Protein & Starch & NDF & $\begin{array}{l}\text { Crude } \\
\text { Fat }\end{array}$ & ISD & SDF & TDF \\
\hline Corn bran & 1.54 & $0.56 \pm 0.00$ & $0.26 \pm 0.01$ & $92.58 \pm 0.35$ & 0.21 & 92.44 & 4.09 & 96.54 \\
\hline Corn stover & 7.29 & $1.29 \pm 0.00$ & $0.16 \pm 0.08$ & $96.92 \pm 0.10$ & 0.10 & 95.30 & 0.89 & 96.20 \\
\hline Rice fiber & 2.25 & $0.91 \pm 0.05$ & $0.21 \pm 0.04$ & $95.11 \pm 0.72$ & 0.04 & 98.63 & 0.00 & 98.63 \\
\hline Wheat bran & 1.05 & $1.72 \pm 0.08$ & $0.36 \pm 0.03$ & $90.48 \pm 0.41$ & 0.00 & 92.03 & 0.00 & 92.03 \\
\hline Wheat straw & 2.27 & $1.75 \pm 0.00$ & $0.05 \pm 0.03$ & $99.75 \pm 0.21$ & 0.36 & 97.55 & 0.00 & 97.55 \\
\hline Switch grass & 1.35 & $1.90 \pm 0.04$ & $0.09 \pm 0.02$ & $98.22 \pm 0.31$ & 0.48 & 99.45 & 0.00 & 99.45 \\
\hline Miscanthus & 1.08 & $0.56 \pm 0.05$ & $0.16 \pm 0.03$ & $98.71 \pm 0.15$ & 0.14 & 99.61 & 0.00 & 99.61 \\
\hline Sugarcane bagasse & 9.90 & $1.91 \pm 0.00$ & 0.060 .04 & $98.55 \pm 0.41$ & 0.25 & 90.82 & 0.00 & 90.82 \\
\hline $\begin{array}{l}\text { Sorghum bran } \\
\text { (Black) }\end{array}$ & 1.76 & $\begin{array}{l}16.49 \pm \\
0.09\end{array}$ & $2.51 \pm 0.05$ & $87.06 \pm 0.14$ & 0.40 & 77.88 & 1.98 & 79.86 \\
\hline $\begin{array}{l}\text { Sorghum bran } \\
\text { (Sumac) }\end{array}$ & 1.07 & $\begin{array}{l}23.82 \pm \\
0.23\end{array}$ & $5.42 \pm 0.24$ & $70.04 \pm 0.85$ & 0.28 & 77.62 & 0.00 & 77.25 \\
\hline $\begin{array}{l}\text { Sorghum bran } \\
\text { (Burgundy) }\end{array}$ & 1.63 & $5.37 \pm 0.06$ & $0.91 \pm 0.09$ & $94.70 \pm 0.18$ & 0.28 & 91.80 & 9.44 & $\begin{array}{l}101.8 \\
9\end{array}$ \\
\hline Barley hulls & 1.00 & $0.89 \pm 0.04$ & $0.09 \pm 0.08$ & $96.54 \pm 0.29$ & 0.15 & 98.51 & 4.15 & $\begin{array}{l}102.6 \\
5\end{array}$ \\
\hline Barley straws & 1.04 & $0.66 \pm 0.03$ & $0.11 \pm 0.04$ & $99.34 \pm 0.39$ & 0.44 & 97.57 & 6.84 & $\begin{array}{l}104.4 \\
1\end{array}$ \\
\hline Carrot pomace & 1.79 & $2.20 \pm 0.07$ & 0.22 & $95.50 \pm 0.59$ & 0.70 & 94.70 & 1.4 & 96.20 \\
\hline
\end{tabular}


Table 3: Sugar composition of CAF Isolated from Plant Materials

\begin{tabular}{|c|c|c|c|c|}
\hline \multirow[t]{2}{*}{ CAF sources } & \multicolumn{4}{|c|}{ Sugar content (Wt. \%) } \\
\hline & Glucose & Xylose & Arabinose & Total \\
\hline Corn bran (Drum Dried CAF) & 52.18 & 31.56 & 12.29 & 96.03 \\
\hline Corn bran (Spray Dried CAF) & 51.60 & 31.08 & 12.00 & 94.68 \\
\hline Corn stover & 66.87 & 21.9 & 2.23 & 91.00 \\
\hline Rice fiber & 64.67 & 20.47 & 2.04 & 87.18 \\
\hline Wheat bran & 34.78 & 31.97 & 13.17 & 79.92 \\
\hline Wheat straw & 60.72 & 23.30 & 2.69 & 86.71 \\
\hline Switch grass & 59.65 & 24.02 & 2.81 & 86.48 \\
\hline Miscanthus & 60.74 & 21.39 & 2.33 & 84.46 \\
\hline Sugarcane bagasse & 57.99 & 23.33 & 2.31 & 83.63 \\
\hline Sorghum bran (Black) & 46.34 & 14.03 & 10.48 & 70.85 \\
\hline Sorghum bran (Sumac) & 54.79 & 11.69 & 7.87 & 74.35 \\
\hline Sorghum bran (Burgundy) & 59.34 & 17.10 & 11.49 & 87.93 \\
\hline Barley hulls & 52.89 & 31.66 & 5.74 & 90.29 \\
\hline Barley straws & 66.70 & 21.74 & 2.52 & 90.96 \\
\hline Carrot pomace & 73.87 & 14.46 & 2.38 & 90.71 \\
\hline
\end{tabular}


Table 4: Glycosyl linkage composition of CAFs from different sources

\begin{tabular}{|c|c|c|c|c|c|}
\hline Glycosyl residue & \multicolumn{5}{|c|}{ Relative peak area $(\%)$} \\
\hline & $\begin{array}{c}\text { Corn bran } \\
\text { CAF }\end{array}$ & $\begin{array}{l}\text { Rice fiber } \\
\text { CAF }\end{array}$ & $\begin{array}{c}\text { Wheat straw } \\
\text { CAF }\end{array}$ & $\begin{array}{c}\text { Miscanthus } \\
\text { CAF }\end{array}$ & $\begin{array}{c}\text { Sugarcane } \\
\text { bagasse CAF }\end{array}$ \\
\hline t-Araf & 5.1 & 1.2 & 2.4 & 1.8 & 1.7 \\
\hline $\mathrm{t}-\mathrm{Xyl} p$ & 5.2 & 0.9 & 1.1 & 0.8 & 0.8 \\
\hline 2-Araf & 2.1 & 0.2 & 0.1 & 0.1 & 0.1 \\
\hline $\mathrm{t}-\mathrm{Glcp}$ & 6.1 & 2.0 & 1.5 & 1.8 & 0.8 \\
\hline 3-Araf & 2.0 & 0.1 & 0.1 & 0.1 & 0.1 \\
\hline $\mathrm{t}-\mathrm{Gal} p$ & 2.9 & 0.2 & 0.2 & 0.1 & 0.1 \\
\hline $\begin{array}{c}\text { 3-Xylp \& 4-Arap or } \\
\text { 5-Araf }\end{array}$ & 0.8 & 0.1 & 0.2 & 0.2 & 0.2 \\
\hline 4-Xylp & 5.9 & 23.7 & 26.1 & 24.3 & 32.8 \\
\hline 3-Glcp & 0.7 & n.d. & 0.7 & 0.4 & 1.0 \\
\hline 3-Galp & 0.3 & n.d. & 0.1 & n.d. & n.d. \\
\hline 4-Manp & 0.7 & 0.1 & n.d. & 0.2 & 0.2 \\
\hline 4-Galp & n.d. & n.d. & n.d. & 0.1 & 0.1 \\
\hline 6-Glcp & 0.1 & n.d. & 0.1 & n.d. & 0.1 \\
\hline 4-Glcp & 55.5 & 66.8 & 60.3 & 65.2 & 53.3 \\
\hline $2,4-\mathrm{Xyl} p$ & n.d. & n.d. & 0.8 & 0.6 & 1.1 \\
\hline 3,4-Xylp & 7.7 & 1.7 & 2.9 & 2.3 & 3.3 \\
\hline 3,4-Glcp & 0.8 & 0.8 & 0.9 & 0.6 & 1.0 \\
\hline 2,4-Glcp & 0.4 & 0.7 & 0.9 & 0.5 & 1.1 \\
\hline 4,6-Glcp \& 2,3,4- & 3.8 & 1.2 & 1.6 & 1.1 & 2.1 \\
\hline
\end{tabular}




\begin{tabular}{|c|c|c|c|c|c|}
\hline Xylp & & & & & \\
\hline Total & 100.0 & 100 & 100 & 100 & 100 \\
\hline
\end{tabular}

n.d. - not detected

545

546

547

548

549

550

551

552

553

554

555

556

557

558

559

560

561

562

563

564

565

566

567

568

569

570

571

572

573

574

Table 5: Water Holding Capacity of CAF Isolated from Plant Materials 


\begin{tabular}{|l|l|}
\hline CAF Sources & Water Held/Sample(g/g) \\
\hline Corn bran (Drum Dried CAF) & $32.8 \pm 1.0$ \\
\hline Corn bran (Spray Dried CAF) & $74.3 \pm 4.5$ \\
\hline Corn stover & $17.7 \pm 1.3$ \\
\hline Rice fiber & $6.4 \pm 0.4$ \\
\hline Wheat bran & $13.9 \pm 0.5$ \\
\hline Wheat straw & $23.7 \pm 0.4$ \\
\hline Switchgrass & $19.8 \pm 0.7$ \\
\hline Miscanthus & $16.8 \pm 0.5$ \\
\hline Sugarcane bagasse & $17.3 \pm 0.7$ \\
\hline Sorghum bran (Black) & $20.0 \pm 0.7$ \\
\hline Sorghum bran (Sumac) & $20.1 \pm 0.2$ \\
\hline Sorghum bran (Burgundy) & $32.8 \pm 1.0$ \\
\hline Barley hulls & $13.8 \pm 0.3$ \\
\hline Barley straws & $21.4 \pm 0.6$ \\
\hline Carrot pomace & $22.9 \pm 1.9$ \\
\hline
\end{tabular}




\begin{tabular}{|c|c|}
\hline CAF Sources & ORAC Value ( $\mu$ mole Trolox/100 gram) \\
\hline Corn bran (Drum Dried CAF) & 1560 \\
\hline Corn bran (Spray Dried CAF) & 868 \\
\hline Corn stover & 362 \\
\hline Rice fiber & 414 \\
\hline Wheat bran & 954 \\
\hline Wheat straw & 4.93 \\
\hline Switchgrass & 649 \\
\hline Miscanthus & 392 \\
\hline Sugarcane bagasse & 427 \\
\hline Sorghum bran (Black) & 633 \\
\hline Sorghum bran (Sumac) & 7.92 \\
\hline Sorghum bran (Burgundy) & 938 \\
\hline Barley hulls & 679 \\
\hline Barley straws & 326 \\
\hline Carrot pomace & 352 \\
\hline
\end{tabular}




\begin{tabular}{|c|c|c|c|}
\hline & $\begin{array}{l}\text { Apparent viscosity at } \\
\text { shear rate of } 1 \mathrm{~s}^{-1}(\mathrm{cP})\end{array}$ & $\begin{array}{l}\text { Flow consistency } \\
\text { index “ } \mathrm{K} \text { " }\left(\text { Pa. } \mathrm{s}^{\mathrm{n}}\right)\end{array}$ & $\begin{array}{l}\text { Flow behavior index } \\
\text { (n) }\end{array}$ \\
\hline $\begin{array}{l}\text { Corn bran (Drum } \\
\text { Dried CAF) }\end{array}$ & 8500 & 10.45 & 0.50 \\
\hline $\begin{array}{l}\text { Corn bran (Spray } \\
\text { Dried CAF) }\end{array}$ & 29100 & 36.45 & 0.25 \\
\hline Corn stover & 1900 & 2.72 & 0.36 \\
\hline Rice fiber & 418 & 1.04 & 0.41 \\
\hline Wheat bran & 639 & 0.78 & 0.41 \\
\hline Wheat straw & 7770 & 11.11 & 0.26 \\
\hline Miscanthus & 1760 & 2.43 & 0.36 \\
\hline Sugarcane bagasse & 5730 & 6.97 & 0.27 \\
\hline Sorghum bran (Black) & 1030 & 1.49 & 0.46 \\
\hline $\begin{array}{l}\text { Sorghum bran } \\
\text { (Sumac) }\end{array}$ & 7250 & 9.35 & 0.45 \\
\hline $\begin{array}{l}\text { Sorghum bran } \\
\text { (Burgundy) }\end{array}$ & 4750 & 6.36 & 0.43 \\
\hline Barley hulls & 540 & 0.727 & 0.38 \\
\hline Barley straws & 3450 & 4.93 & 0.32 \\
\hline Carrot pomace & 8620 & 13.32 & 0.26 \\
\hline Sugar-beet bagasse & 11700 & 18.31 & 0.32 \\
\hline
\end{tabular}

599 Figure 1 shows a generic scheme for the preparation of cellulosic arabinoxylan fiber (CAF). 
600 Figure 2(a) shows the effects of drying technique and shearing on corn CAF viscosity:

601 Comparison of drum dried (DD) and spray dried (SD) CAF suspensions prepared with and 602 without shear.

603 Figure 2(b) shows the effects of drying technique and shearing on sorghum CAF viscosity:

604 Comparison of drum dried (DD) and spray dried (SD) CAF suspensions prepared with and 605 without shear. Data are average of three runs with error bars.

606

607

608

609

610

611

612

613

614

615

616

617

618

619

620

621

622

623

624

625

626

627

628

629

630

631

632 9. Figures

633 Figure 1 


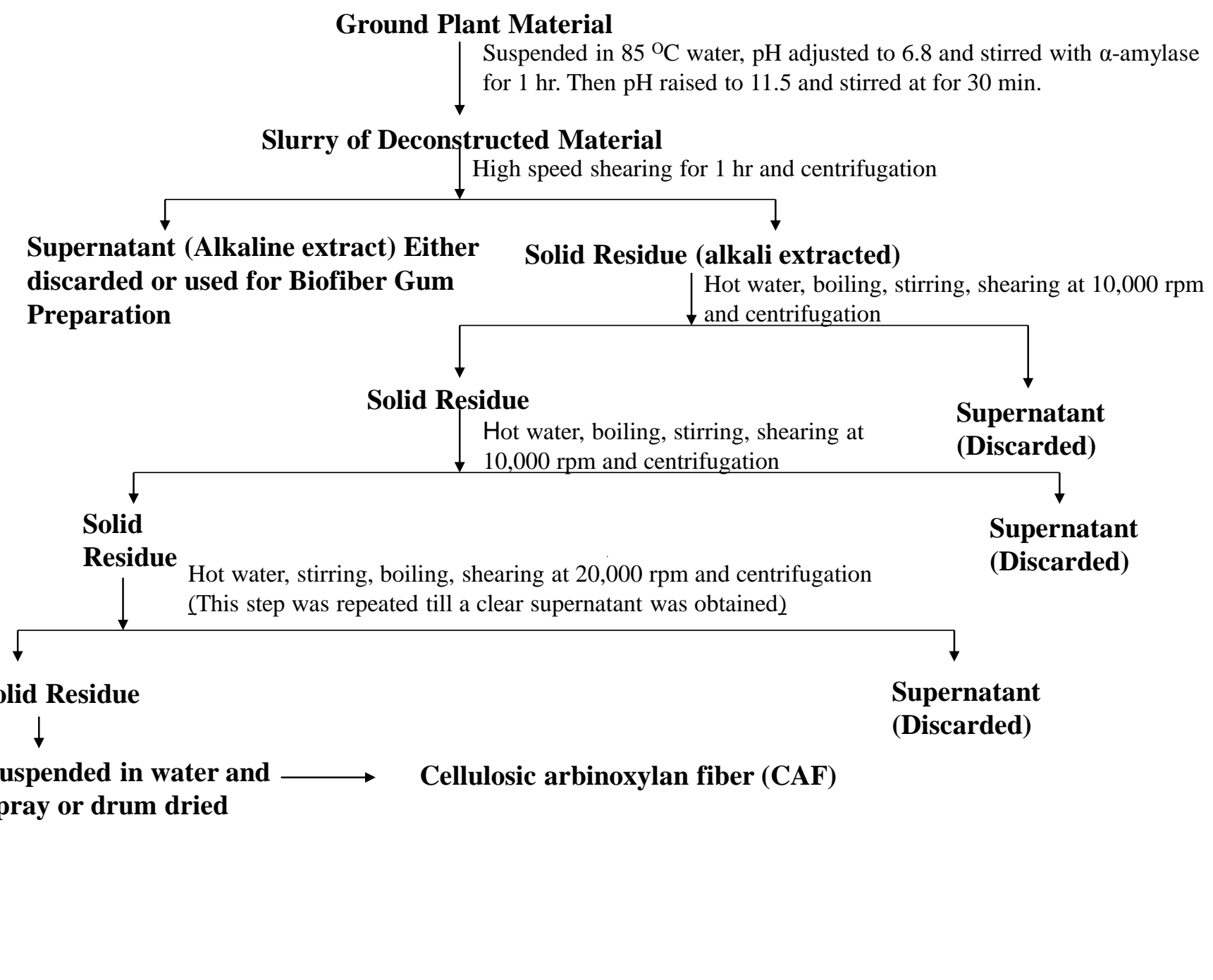


638 Figure 2(a)

639

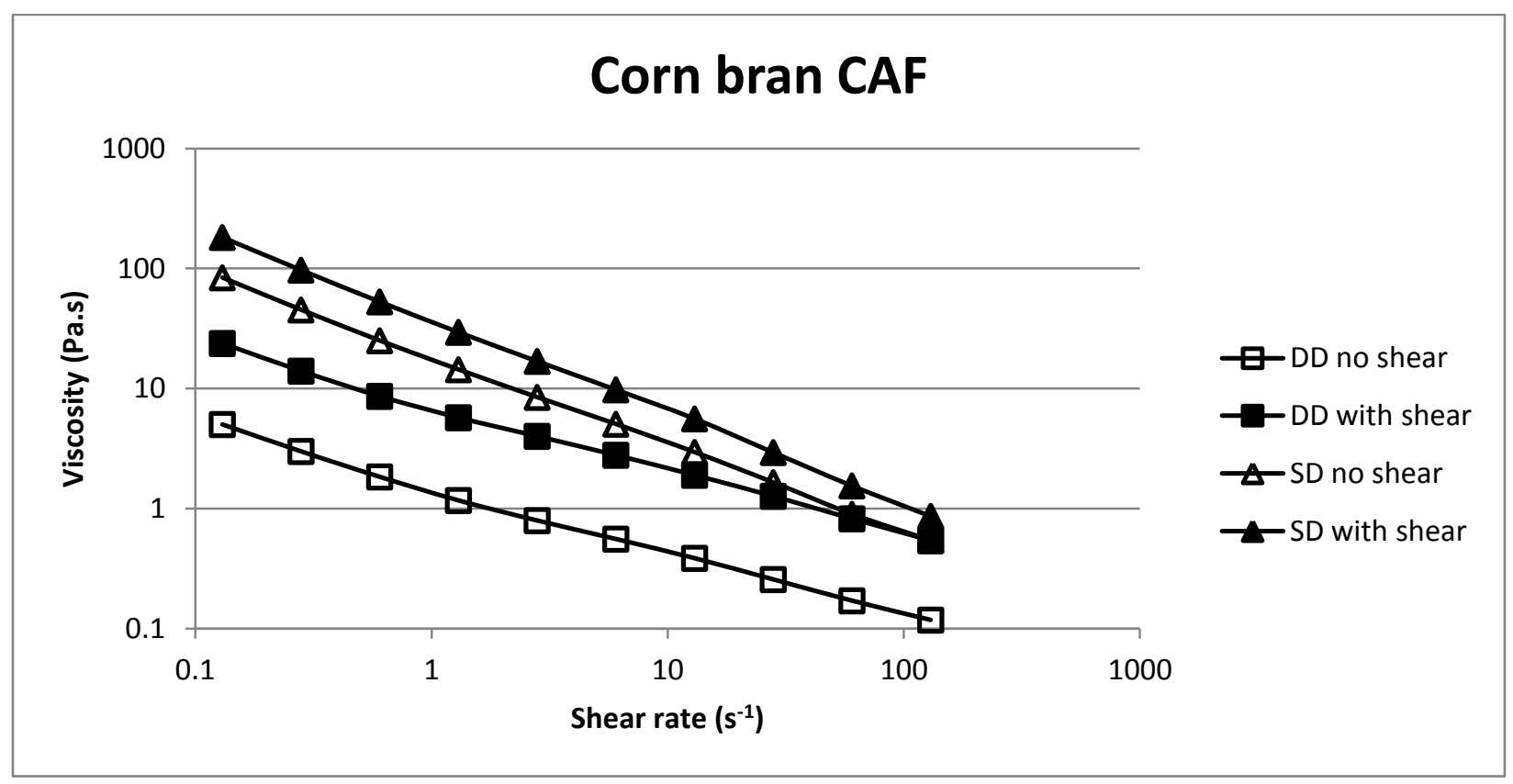

640

641 Figure 2(b)

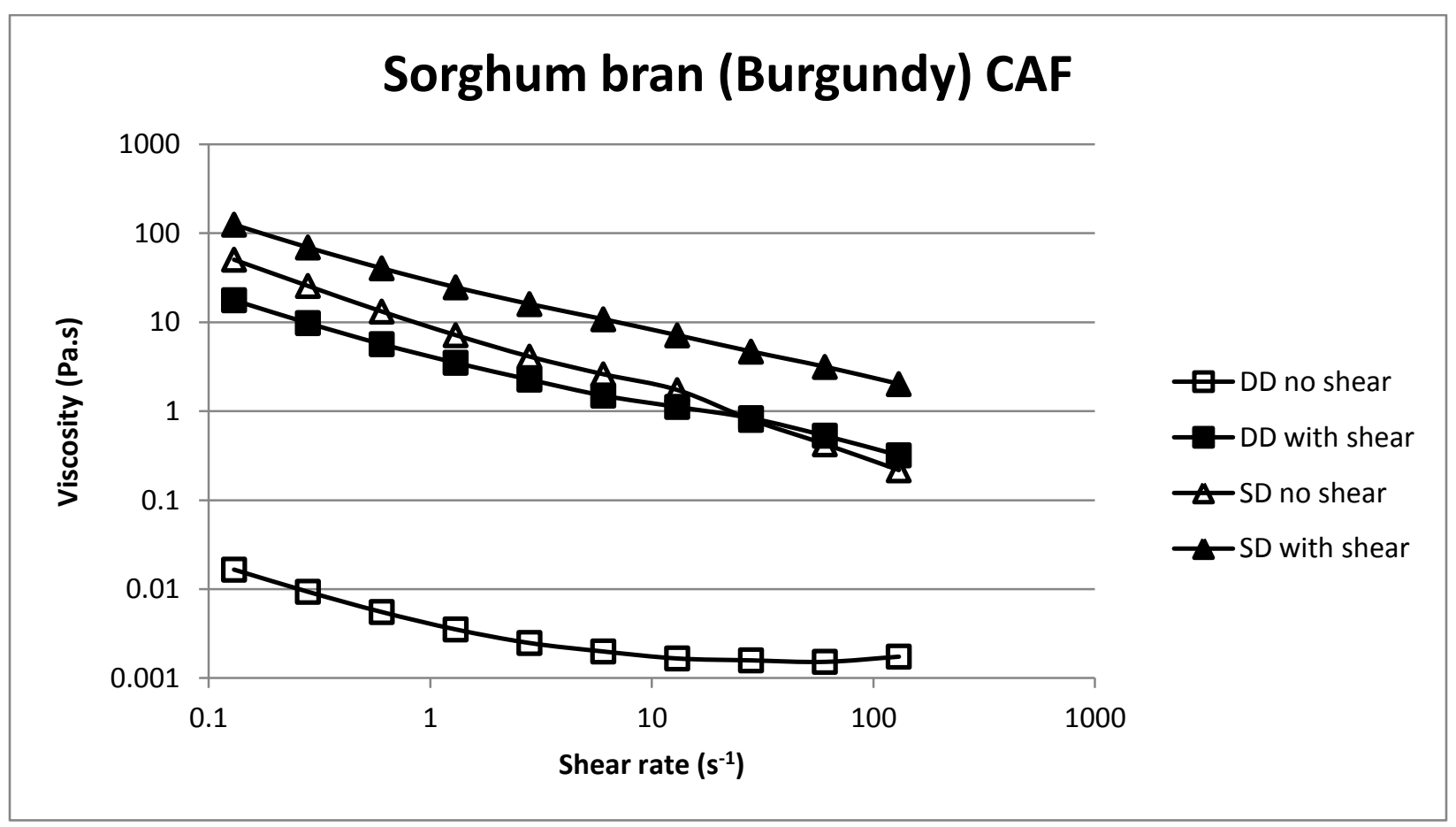

642

643 


\section{Captions}

Figure 1 shows a generic scheme for the preparation of cellulosic arabinoxylan fiber (CAF).

Figure 2(a) shows the effects of drying technique and shearing on corn CAF viscosity: Comparison of drum dried (DD) and spray dried (SD) CAF suspensions prepared with and without shear.

Figure 2(b) shows the effects of drying technique and shearing on sorghum CAF viscosity: Comparison of drum dried (DD) and spray dried (SD) CAF suspensions prepared with and without shear. Data are average of three runs with error bars. 